Check for updates

Cite this: RSC Adv., 2018, 8, 9402

\title{
Investigation of ultra-low friction on steel surfaces with diketone lubricants
}

\begin{abstract}
Shumin Zhang, ${ }^{a}$ Chenhui Zhang, (D) *a $\mathrm{Ke} \mathrm{Li}^{\mathrm{bc}}$ and Jianbin Luo ${ }^{\mathrm{a}}$
In this study, the lubricating properties of ethylacetophenone (EAP) solutions with different benzoylacetone (BZA) concentrations on steel surfaces were investigated. The results indicate that with an increase in the BZA concentration in the solution, the friction coefficient decreases, and an ultra-low friction coefficient ( $\mu \approx 0.005-0.008$ ) is obtained for the solution with $50 \mathrm{wt} \%$ BZA concentration. This demonstrates that both the applied normal load and the sliding velocity have significant influence on the realization of ultra-low friction for the 50 wt\% BZA solution. Furthermore, the chemical states of the friction surfaces and the components of the $50 \mathrm{wt} \%$ BZA solution were detected via X-ray photoelectron spectroscopy (XPS) and infrared spectroscopy (IR), respectively. The analyses reveal that a tribochemical reaction occurs between the BZA molecules and the rubbing surfaces, and the chelate not only can disperse in the solution, but can also form chemical adsorption layers on the rubbing surfaces. In addition, the mechanism of ultra-low friction has been discussed based on the results of these analyses. Both the influence of the hydrodynamic effect and the existence of chemically absorbed films on the steel surfaces lead to a reduction in the friction coefficient. This study reveals that diketone is a promising lubricant for ultralow friction and has great potential in industrial applications.
\end{abstract}

Received 4th December 2017 Accepted 17th February 2018

DOI: 10.1039/c7ra13027a

rsc.li/rsc-advances hydrated ion lubrication, ${ }^{\mathbf{1 1}}$ polymer brush immersed in water, ${ }^{\mathbf{1 2}}$ ceramic materials with water lubrication, ${ }^{\mathbf{1 3 , 1 4}}$ phosphoric acid solution, ${ }^{15}$ a mixture of polyhydroxy alcohol and acid, ${ }^{16-18}$ and some types of biological mucus. ${ }^{19,20}$

Water as a lubricant has many excellent attributes such as safety, non-toxicity, low-cost, environmental friendliness, and cooling performance. However, water-based lubricants are also subject to certain restrictions. For instance, many mechanical parts are susceptible to water-induced corrosion in engineering applications. On the contrary, oil-based lubricants have been widely used in practical mechanical systems, such as gears and bearings, due to their non-perishable and non-susceptible characteristic to ambient temperature and humidity. However, the minimum friction coefficient of the traditional oil-based lubricants is typically above 0.04 due to their high viscositypressure coefficient and viscosity. ${ }^{6}$ Although studies on superlubricity in oil-based lubricants have not attracted widespread attention, some innovative results have been obtained. Li et al. found that super-low friction $(\mu \approx 0.004)$ of silicone oil was achieved between a $\mathrm{Si}_{3} \mathrm{~N}_{4}$ ball and glass disc by running-in with an acid solution. ${ }^{21}$ Moreover, the superlubricity mechanism was proposed, where a micro-slope plain bearing between two sliding surfaces was generated by the running-in process with an acid solution, and a hydrodynamic film of silicone oil was formed at a certain speed. Recently, Li et al. found that the friction coefficient of 1,3-diketone lubricants on steel surfaces was 0.005 , which was much lower than that of a variety of standard oil-based lubricants. ${ }^{22-24}$ This is mainly attributed to
${ }^{a}$ State Key Laboratory of Tribology, Tsinghua University, Beijing, 100084, China. E-mail: chzhang@tsinghua.edu.cn

${ }^{b}$ Intelligent Transport Systems Research Center, Wuhan University of Technology, Wuhan, 430063, China

${ }^{c}$ Reliability Engineering Institute, National Engineering Research Center for Water Transport Safety, MOST, Wuhan, 430063, China 
the formation of complexes between 1,3-diketones and iron ions on the steel surfaces during the friction test. The chelate has excellent thermodynamic stability, which not only can be used to improve the stability of oil-based lubricants, but can also be conducive to the realization of ultra-low friction. ${ }^{25}$

At present, the study of liquid superlubricity mainly focuses on water-based lubricants or oil-based lubricants under some specific environments; however, these lubricants do not satisfy industrial applications and cannot result in direct economic benefits. In comparison, diketone lubricants have great advantages in industrial areas although their friction properties have not attracted significant attention. In this regard, the present study highlights the sliding friction and wear behaviors of ethylacetophenone (EAP) solutions with different benzoylacetone (BZA) concentrations on steel surfaces by controlling the tribotesting conditions (e.g. velocity and load). In detail, the 3D morphologies and the chemical states of the rubbing surfaces were analyzed using white-light interferometry and X-ray photoelectron spectroscopy, respectively. A component analysis of the solution with $50 \%$ BZA concentration before and after the friction test was conducted using infrared spectroscopy. After this, the mechanism of ultra-low friction has been discussed based on the results of these analyses.

\section{Materials and method}

$\beta$-Diketone is a bidentate ligand, which can form a stable sixmembered ring chelate with metal ions. In this study, BZA is selected as the experimental model because its molecular structure is very similar to that of the superlubricious matter reported in the literature. ${ }^{22-24}$ It is generally believed that $\beta$-diketone compounds can appear in both the enol and keto tautomeric forms due to the active chemical properties of the methylene hydrogen atoms between two carbonyl groups. It can be seen that there is a six-membered ring linked by hydrogen bonds in the enol form, as shown in Fig. 1(a). In this study, BZA is in the form of a light-yellow solid purchased from Alfa Aesar, and it has good solubility in the EAP solution that is mainly attributed to the similar molecular structures of these two substances. The chemical formulas of BZA and EAP are shown in Fig. 1. Herein, EAP was used as a solvent, and BZA was used

(a)

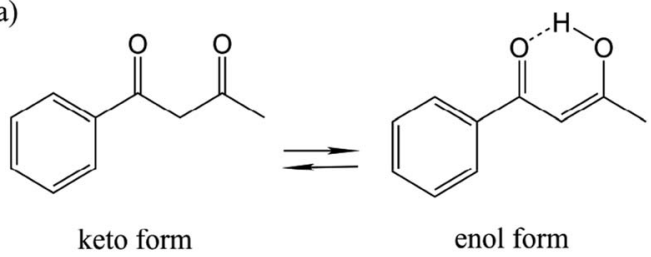

(b)

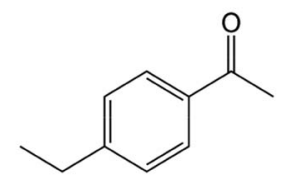

Fig. 1 Molecular structures of (a) BZA and (b) EAP. as a solute. Moreover, three different concentrations of $10 \mathrm{wt} \%$, $30 \mathrm{wt} \%$, and $50 \mathrm{wt} \%$ were prepared for comparison.

The friction coefficient was measured using a Universal Micro Tribotester (UMT5, Bruker, USA) in the rotation mode of ball-on-disc under solutions with different BZA concentrations. The ball was made of GCr15 bearing steel with a diameter of $12.7 \mathrm{~mm}\left(R_{\mathrm{a}}=20 \mathrm{~nm}\right)$. The disc was also made of GCr15 with the hardness of HRC 60, which was polished by an automatic polishing-grinding machine to achieve the surface roughness $\left(R_{\mathrm{a}}\right)$ of $15 \mathrm{~nm}$. Before tribotesting, the ball and the disc were cleaned with acetone and ethanol in an ultrasonic bath for $10 \mathrm{~min}$, respectively, and then dried with compressed air. The solution was added between the ball and the disc with a volume of $5 \mu \mathrm{L}$ at the beginning of the tests. The applied normal load was $3 \mathrm{~N}$, and the rotation speed of the substrate was $960 \mathrm{rpm}$ with a rotation radius of $5 \mathrm{~mm}$, corresponding to a linear speed of $502.4 \mathrm{~mm} \mathrm{~s}^{-1}$. Based on the Hertz contact theory, the initial maximum contact pressure was about 576.5 MPa under the load of $3 \mathrm{~N}$. All tests were carried out at room temperature $\left(25^{\circ} \mathrm{C}\right)$.

The 3D morphology of the rubbing surface was observed using a white-light interferometer (NeXView, Zygo). The radius of curvature and the surface roughness of the worn region on the steel balls were obtained. The elemental compositions and the chemical bonding state inside the wear tracks were detected using an X-ray photoelectron spectrometer (XPS, PHI QUANTERA II). Before the XPS test, the samples were ultrasonically cleaned in an acetone and ethanol bath. To further analyze the changes in the solution with a $50 \mathrm{wt} \%$ BZA concentration before and after the friction test, infrared spectroscopy (IR, Bruker) was conducted with spectral resolution better than $0.16 \mathrm{~cm}^{-1}$.

\section{Results and discussion}

\subsection{Tribological properties of EAP solutions with different BZA concentrations}

The evolution of the friction coefficients achieved between the steel ball and steel disc lubricated by EAP solutions with different BZA concentrations is shown in Fig. 2. It can be seen that the friction coefficient is significantly influenced by the BZA concentration in the solution. When the friction pair was lubricated with pure EAP, the friction coefficient stably remained at 0.11 after the running-in period. When the BZA concentration was $10 \mathrm{wt} \%$ in the EAP solution, the friction coefficient fluctuated at around 0.1 at the beginning of the test. After this, it decreased to 0.07 and remained constant until the end of the test. The friction coefficient decreased from 0.13 to 0.025 after the running-in process when the BZA concentration was $30 \mathrm{wt} \%$. With a further increase in the BZA concentration to $50 \mathrm{wt} \%$, the friction coefficient decreased significantly to below 0.01 after the running-in process of $40 \mathrm{~min}$. Moreover, the ultra-low friction ( $\mu \approx 0.005-0.008$ ) could be maintained stably until the end of the test. The abovementioned results indicate that BZA can improve the lubricating performance of EAP, and the friction reduction is closely related to the BZA concentration in the EAP solution. In addition, the solution changed from initial light-yellow to red after the tests. For the solution with a BZA concentration of $50 \mathrm{wt} \%$, its color even became deep red. In contrast, the color of 


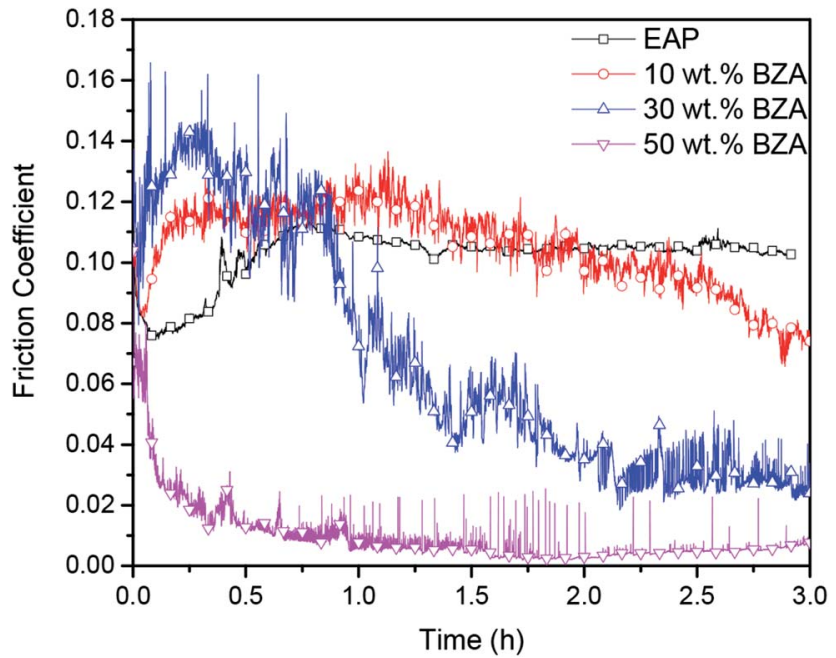

Fig. 2 Friction coefficient curves for the steel surfaces lubricated by EAP solutions with different BZA concentrations.

the pure EAP did not change during the test. Moreover, no debris was observed during the test when BZA was added to the solutions. It is speculated that a tribochemical reaction occurs between the BZA molecules and the rubbing surfaces, which may play a key role in achieving the low friction.

The 3D morphologies of the wear scars and tracks on the frictional surfaces are shown in Fig. 3. It can be seen that both the steel ball and the disc were worn in all the cases. When the solution with $10 \mathrm{wt} \%$ BZA concentration was applied, a circular worn region with a diameter of $280 \mu \mathrm{m}$ was formed, as shown in Fig. 3(a). Moreover, there were numerous micro-grooves inside the wear track with the width of $300 \mu \mathrm{m}$, as shown in Fig. 3(d). When the BZA concentration was $30 \mathrm{wt} \%$ in the solution, the diameter of the wear scar and the width of the wear track were about $550 \mu \mathrm{m}$ and $450 \mu \mathrm{m}$, as shown in Fig. 3(b) and (e), respectively. With an increase in the BZA concentration to $50 \mathrm{wt} \%$, a wear scar with a diameter of $590 \mu \mathrm{m}$ was observed on the steel ball, and the width of the wear track was $560 \mu \mathrm{m}$ on the steel disc, as shown in Fig. 3(c) and (f), respectively. These results indicate that with an increase in the BZA concentration in solution, the wear of ball materials increases obviously. However, a smoother worn surface $\left(R_{\mathrm{a}}=15 \mathrm{~nm}\right)$ on the steel ball was obtained under the solution with $50 \mathrm{wt} \%$ BZA concentration as compared to the cases with $30 \mathrm{wt} \%$ and $10 \mathrm{wt} \% \mathrm{BZA}$ concentration ( $R_{\mathrm{a}}$ of $34 \mathrm{~nm}$ and $45 \mathrm{~nm}$, respectively). Thus, it is speculated that chemical polishing may occur during the test due to the presence of BZA. In addition, the depths of the wear tracks on the steel discs were about $0.48 \mu \mathrm{m}, 0.54 \mu \mathrm{m}$, and 0.93 $\mu \mathrm{m}$ when the BZA concentrations of the solution were $50 \mathrm{wt} \%$, $30 \mathrm{wt} \%$, and $10 \mathrm{wt} \%$, respectively. It can be seen that more uniform grooves inside the wear track are obtained when the EAP solution with a $50 \mathrm{wt} \% \mathrm{BZA}$ concentration is applied on the frictional surfaces.

The initial maximum contact pressure was calculated to be 576.5 MPa using the Hertz contact theory before the friction test. The curvature radii of the wear scars on the steel balls were obtained from the 3D morphology shown in Fig. 3. Then, the contact pressures after the friction test were calculated using the radii of curvature and the Hertz theory. When the BZA concentrations were $10 \mathrm{wt} \%, 30 \mathrm{wt} \%$, and $50 \mathrm{wt} \%$ in solution, the maximum contact pressures after the tests decreased to 103.9 MPa, 88.3 MPa, and 55.3 MPa, respectively. It can be seen that the decrease in the contact pressure is mainly due to the expansion of the contact area. The results show that with an increase in the BZA concentration in the solution, the contact pressure decreases significantly; this results in a dramatic reduction in the friction coefficient.

The influence of the sliding velocity and the applied load on the friction coefficient of the EAP solutions with different BZA concentrations was investigated. It can be seen from Fig. 4(a) that the typical Stribeck curve is obtained for the relationship between friction coefficient and velocity. For all four solutions, the friction coefficient decreased as the velocity increased from $31.4 \mathrm{~mm} \mathrm{~s}^{-1}$ and reached the minimum when the velocity was around $565.2 \mathrm{~mm} \mathrm{~s}^{-1}$. Subsequently, the friction coefficient increased with the continuously increasing velocity. It can also be found that super-low friction (friction coefficient less than 0.01 ) is achieved only in the case of lubrication with the solution
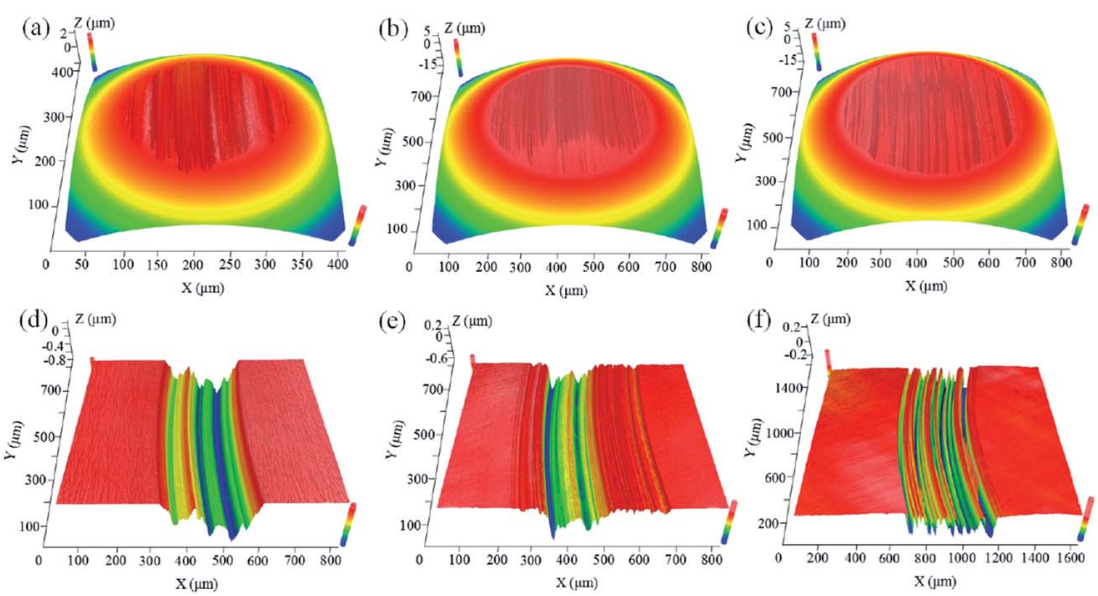

Fig. 3 3D morphologies of the friction pairs ( $(a)-(c)$ steel balls and $(d)-(f)$ steel discs) lubricated by EAP solutions with different BZA concentrations: (a) and (d) $10 \mathrm{wt} \%$, (b) and (e) $30 \mathrm{wt} \%$, and (c) and (f) $50 \mathrm{wt} \%$. 

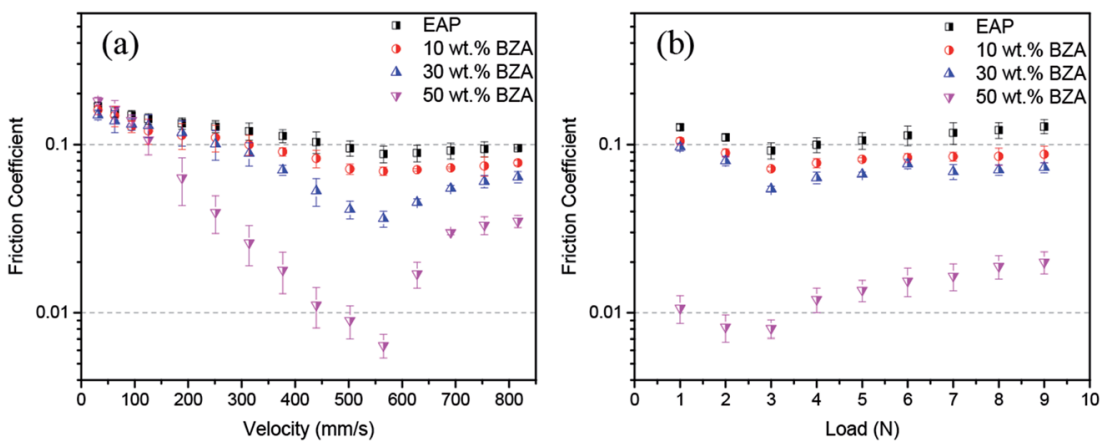

Fig. 4 Effects of (a) velocity under the load of $3 \mathrm{~N}$ and (b) load at a linear velocity of $502.4 \mathrm{~mm} \mathrm{~s}^{-1}$ on the friction coefficient lubricated by EAP solutions with different BZA concentrations.

containing $50 \mathrm{wt} \%$ BZA concentration. From the Stribeck curve shown in Fig. 4(a), it is deduced that the lubrication state is mixed lubrication when super-low friction is obtained. The dependence of the friction coefficient on the applied load also presents a typical Stribeck curve. The minimum friction coefficient was achieved at the load of $3 \mathrm{~N}$ for all four solutions. In addition, an ultra-low friction coefficient $(\mu \approx 0.008)$ was achieved at the load of $2 \mathrm{~N}$ or $3 \mathrm{~N}$ when the BZA concentration in the EAP solution was $50 \mathrm{wt} \%$. These results show that both the sliding velocity and the applied load have important influence on the friction coefficient, particularly on the realization of super-low friction for EAP solutions with 50 wt\% BZA concentration.

\subsection{XPS analysis inside wear tracks after lubrication by EAP solutions with different BZA concentrations}

It can be hypothesized that a tribochemical reaction can occur between 1,3-diketones and iron ions during the friction process. ${ }^{25}$ As can be seen in Fig. 5, a complex with stable thermodynamic properties was formed due to its octahedral structure with the coordination bond between the carbonyl group and iron ion. To verify the existence of the chemically adsorbed film on the steel surface after the friction test, XPS analysis was performed. The types of compositions and amounts of functional groups adsorbed on the surfaces can be determined by the binding energy, which is sensitive to the chemical environment of the atoms.

The peaks of $\mathrm{C} 1 \mathrm{~s}$ on the initial surface and the wear tracks under solutions with different BZA concentrations are shown in Fig. 6. Gaussian multimodal fitting was used to separate the peaks to obtain information about the chemical states of the wear tracks. The peak of the $\mathrm{C} 1 \mathrm{~s}$ spectrum was decomposed into several different chemical environments such as $\mathrm{C}-\mathrm{H}, \mathrm{C}-\mathrm{C}$, and $\mathrm{C}=\mathrm{O}$. The positions of these signals are well consistent with those of similar compounds reported in the literature. ${ }^{21,26,27}$ It should be noted that the same atom in different chemical environments can give rise to discrete components. The existence of the adsorbed film was estimated according to the chemical shift of the $\mathrm{C} 1 \mathrm{~s}$ peak.

The peaks of the $\mathrm{C}$ 1s spectra mainly appeared in two chemical environments $(\mathrm{C}=\mathrm{C}$ and $\mathrm{C}-\mathrm{C} / \mathrm{C}-\mathrm{H})$ on the initial surface, as depicted in Fig. 6(a). Moreover, the binding energies of these two signals were $284.6 \mathrm{eV}$ and $285.3 \mathrm{eV}$, and their area fractions were $85.88 \%$ and $14.12 \%$, respectively. It can be seen in Fig. 6 and Table 1 that the area fractions of $\mathrm{C}=\mathrm{C}$ and $\mathrm{C}-\mathrm{C} / \mathrm{C}-$ $\mathrm{H}$ change significantly when the surfaces are lubricated by EAP solutions with different BZA concentrations. Due to the existence of $\mathrm{C}=\mathrm{O}$ in the BZA molecular structure, the peaks of the carbon atoms in the 2 and 3 bonding states (Fig. 6(e)) shifted to higher binding energies. With an increase in the BZA concentration in the solution, the area fraction of $\mathrm{C}=\mathrm{O}$ increased evidently, whereas the area fractions of $\mathrm{C}=\mathrm{C}$ and $\mathrm{C}-\mathrm{C} / \mathrm{C}-\mathrm{H}$ changed in the opposite trend. Specifically, when the BZA concentration in the solution was $10 \mathrm{wt} \%, 30 \mathrm{wt} \%$, and $50 \mathrm{wt} \%$, the area fractions of $\mathrm{C}=\mathrm{O}$ were $12.4 \%, 23.05 \%$, and $26.12 \%$, respectively. It should be mentioned that there is a peak at $282.9 \mathrm{eV}$ with the area fraction of $5.01 \%$ for the solution with $30 \mathrm{wt} \%$ BZA concentration, which corresponds to metal carbide. Moreover, when the BZA concentration was up to $50 \mathrm{wt} \%$, this peak for the metal carbide was observed with the area fraction of $2.2 \%$. In addition, there was a pi-pi* peak at $292.2 \mathrm{eV}$ when the BZA concentration was $50 \mathrm{wt} \%$. This is mainly attributed to the existence of a pi bond in the carbonyl group itself, which means that an empty anti orbital pi* is present. The oxygen atom in the carbonyl group can provide a lone pair of electrons to form a coordination bond with the metal iron ion $\left(\mathrm{Fe}^{3+}\right)$. The formation of the coordinate bond can promote electronic transition from the pi to pi* orbital, and then, the peak of pi-pi* can be detected at around $292 \mathrm{eV}$. These results indicate that the BZA molecules are adhered inside the wear track through coordination bonds. It is speculated that when the BZA concentration is $50 \mathrm{wt} \%$ in the solution, complete chemically adsorbed layers of BZA molecules can be formed on the worn

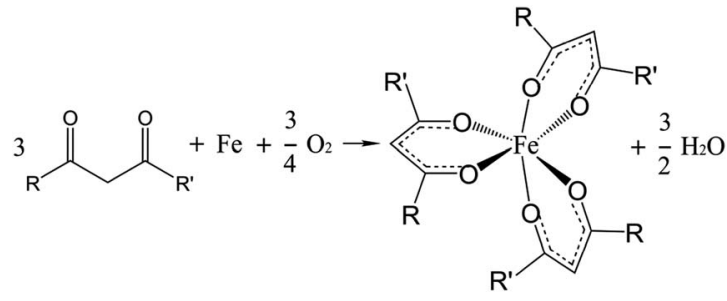

Fig. 5 Chemical reaction of the 1,3-diketones and iron during the tribological test. $\mathrm{R}$ represents phenyl-p-alkyl and $\mathrm{R}^{\prime}$ represents alkyl chains with different chain lengths. 

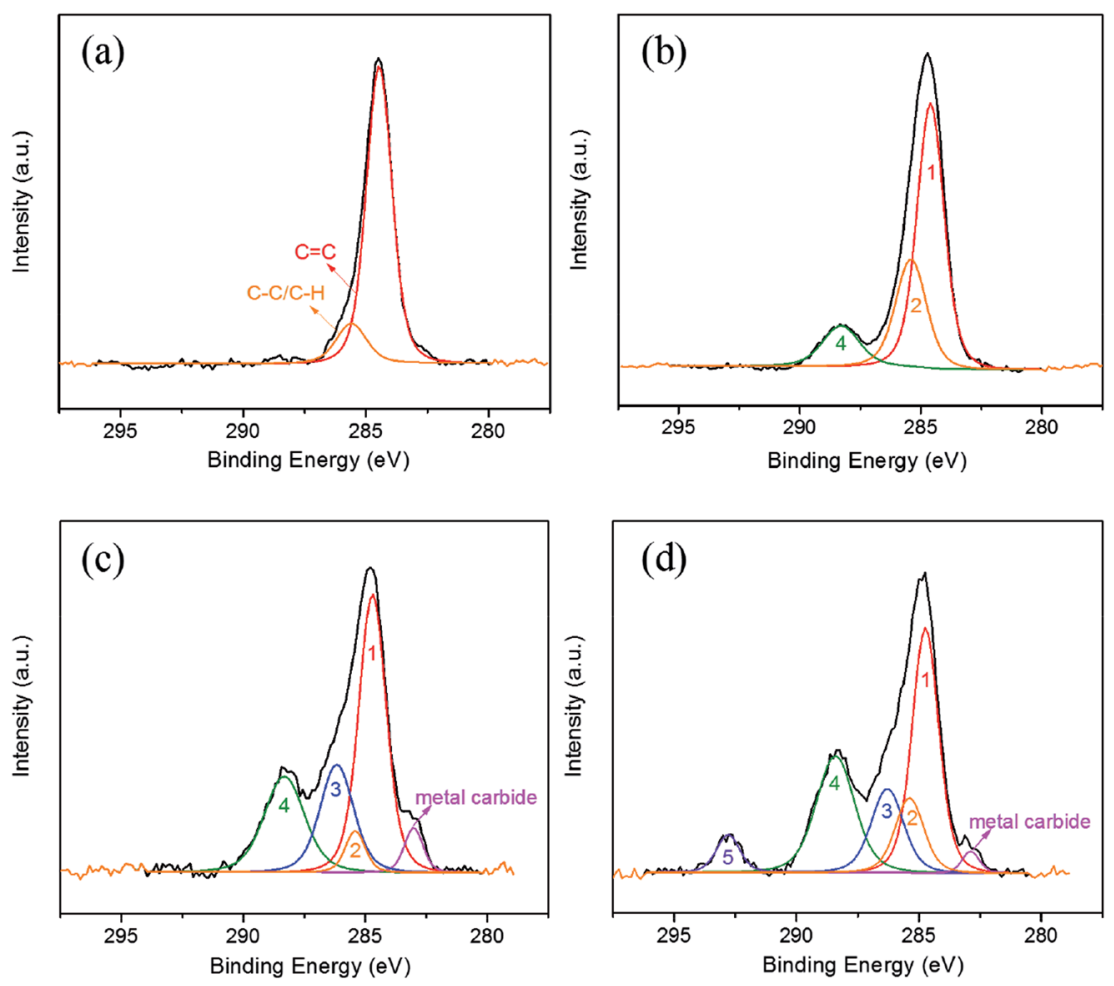

(e)

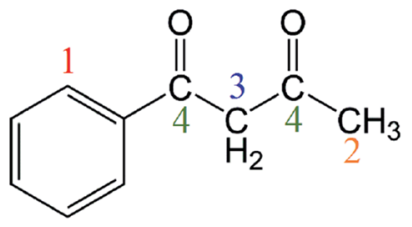

Fig. 6 XPS analysis of the $C$ 1s spectra measured from the (a) initial surface and as-formed wear tracks after lubrication by EAP solutions with different BZA concentrations of (b) $10 \mathrm{wt} \%$, (c) $30 \mathrm{wt} \%$, and (d) $50 \mathrm{wt} \%$. The C 1s components refer to the carbon atoms numbered in the molecular structure (e).

surface, which are conducive to the realization of an ultra-low friction coefficient.

\subsection{IR analysis of the EAP solution with $50 \mathrm{wt} \% \mathrm{BZA}$ concentration before and after the friction test}

As abovementioned, the EAP solution with 50 wt\% BZA concentration changed from light-yellow to deep red during the friction test. To further explain this phenomenon and confirm the tribochemical reaction, the component analysis of the EAP solution with $50 \mathrm{wt} \%$ BZA concentration before and after the friction test was investigated via infrared spectroscopy (IR), as shown in Fig. 7. For the solution before the friction test, it can be seen that there is a strong absorption band at $1679 \mathrm{~cm}^{-1}$, which is related to the stretching vibration of the $\mathrm{C}=\mathrm{O}$ bond both in the EAP molecule and the keto form of the BZA molecule. However, the position of this absorption band was slightly lower than normal due to the conjugation between the aromatic ring and carbonyl group. In addition, BZA molecules can appear in both the enol and keto tautomeric forms. In the enol form of the BZA molecule, the stretching vibration of the $\mathrm{C}=\mathrm{O}$ bond and in-plane deformation vibration of the $\mathrm{O}-\mathrm{H}$ bond are assigned to the absorption bands at $1570 \mathrm{~cm}^{-1}$ and $1606 \mathrm{~cm}^{-1}$, respectively. It can be found that the absorption bands of $\mathrm{C}=\mathrm{O}$ are different in the enol and keto forms of the BZA molecule due

Table 1 Parameters of the component $C$ 1s peak on the surfaces lubricated by EAP solutions with different BZA concentrations (the bonding states of carbon atoms displayed in Fig. 6(e))

\begin{tabular}{|c|c|c|c|c|c|c|c|}
\hline & & \multicolumn{6}{|c|}{ C 1s component } \\
\hline & & 1 & 2 & 3 & 4 & 5 & Metal carbide \\
\hline \multicolumn{2}{|l|}{ Binding energy (eV) } & 284.6 & 285.3 & 286 & 288.3 & 292.2 & 282.9 \\
\hline \multirow[t]{3}{*}{ Area fraction (\%) } & $10 \mathrm{wt} \% \mathrm{BZA}$ & 54 & 33.6 & - & 12.4 & - & - \\
\hline & $30 \mathrm{wt} \% \mathrm{BZA}$ & 45.54 & 4.9 & 21.5 & 23.05 & - & 5.01 \\
\hline & $50 \mathrm{wt} \% \mathrm{BZA}$ & 38.18 & 12.6 & 15.81 & 26.12 & 5.09 & 2.2 \\
\hline
\end{tabular}




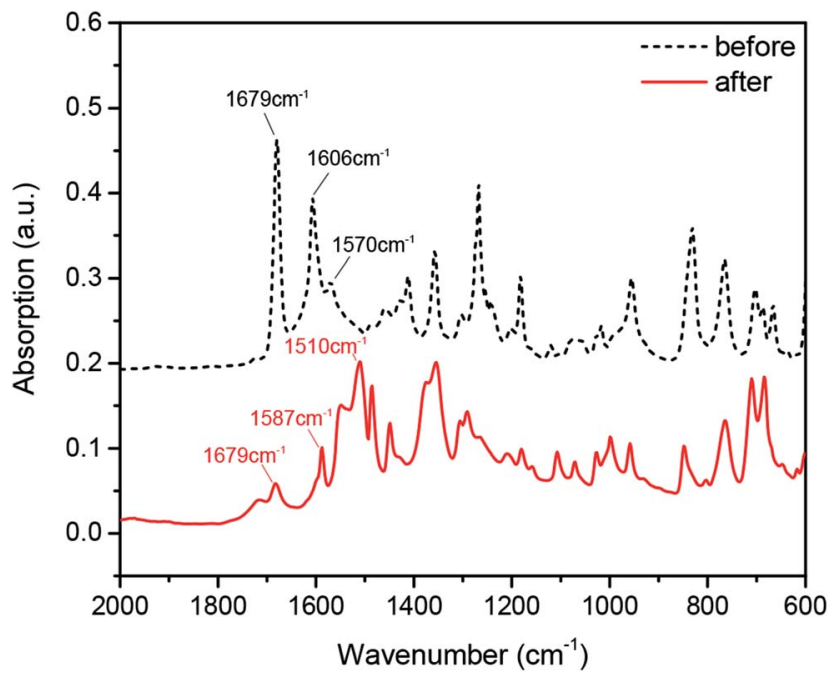

Fig. 7 IR spectra of the EAP solution with 50 wt\% BZA concentration before and after the friction test.

to the formation of a six-membered ring hydrogen bond between the carbonyl and hydroxyl group in the enol form.

For the solution after the friction test, the characteristic peak at $1679 \mathrm{~cm}^{-1}$ was still detected, which mainly corresponded to the stretching vibration of the $\mathrm{C}=\mathrm{O}$ bond in the EAP molecule. However, the intensity of the absorption band at $1606 \mathrm{~cm}^{-1}$ obviously weakened or even disappeared. This result indicates that the structure of the BZA molecules changes in the EAP solution; this confirms the occurrence of a tribochemical reaction during the friction test. The oxygen atom in the carbonyl group of the BZA molecule can provide a lone pair of electrons to form a coordination bond with iron ions. Due to the formation of the coordination bond, the electron cloud density of the coordination atom (oxygen atom of $\mathrm{C}=\mathrm{O}$ ) decreases; this results in the shift of the stretching vibration of $\mathrm{C}=\mathrm{O}$ to the low absorption band at $1587 \mathrm{~cm}^{-1}$. In addition, a new absorption peak at $1510 \mathrm{~cm}^{-1}$ was observed for the solution after the friction test. This is mainly attributed to the formation of a chelate, which may reduce the symmetry of the ligands and make the inactive infrared vibrational ligands become active.

Thus, the IR spectra results indicate that the chemical states of the EAP solution with $50 \mathrm{wt} \%$ BZA concentration changes significantly during the friction test. Combined with the XPS analysis, it is reasonable to conclude that the tribochemical reaction between the BZA molecules and iron ions is confirmed, and the as-formed chelate not only can disperse in the solution, but can also form chemically adsorbed layers on the rubbing surfaces.

\subsection{The ultra-low friction mechanism of the EAP solution with 50 wt $\%$ BZA concentration}

Li $e t$ al. established the liquid superlubricity region depending on the pressure and the pressure-viscosity coefficient, and the superlubricity of oil-based lubricants could only be achieved at low pressures due to their high pressure-viscosity coefficients. ${ }^{28}$ In our present study, ultra-low friction $(\mu \approx 0.005-0.008)$ was obtained when the maximum contact pressure decreased to 55.3 MPa with the progress of the tribotest. To study the state of lubrication and the ultra-low friction mechanism, the theoretical minimum film thickness was calculated using the Hamrock-Dowson formula. ${ }^{29}$ The viscosity of the EAP solution with $50 \mathrm{wt} \%$ BZA concentration after the friction test was $3.82 \mathrm{mPa} \mathrm{s}$, which was measured by a rotary rheometer (MCR302, Anton Paar) with a cone-plate geometry (CP50-1). The minimum film thickness was calculated to be about $60.4 \mathrm{~nm}$ when the applied normal load and velocity were $3 \mathrm{~N}$ and $502.4 \mathrm{~mm} \mathrm{~s}^{-1}$, respectively. The surface roughness of the steel ball and steel disc after the test was $15 \mathrm{~nm}$ and $51 \mathrm{~nm}$, respectively, which were measured by a white-light interferometer. Thus, the ratio of the minimum film thickness to the combined surface roughness was 1.14, which illustrated that the lubrication was in the regime of mixed lubrication. Thus, the friction coefficient is influenced by the fluid effect and the asperity contact in mixed lubrication.

Based on the previous results, it can be found that the concentration of BZA in the EAP solution has an important influence on the friction coefficient. Only when the concentration of BZA in the EAP solution reaches a certain value, an ultralow friction coefficient will be achieved; this is mainly due to the occurrence of a tribochemical reaction between the BZA molecules and iron ions. Moreover, the running-in time was significantly shortened, and the diameter of wear scar on the steel ball obviously increased when the EAP solution with $50 \mathrm{wt} \%$ BZA concentration was applied, as shown in Fig. 2 and 3(c). In this case, the proportion of $\mathrm{C}=\mathrm{O}$ in the solution increases dramatically, which can increase the rate of the tribochemical reaction of $\mathrm{C}=\mathrm{O}$ with iron ions. As a result, a large plane on the steel ball is generated in a short time. In addition, stable adsorbed tribo-chemical layers are formed on the steel surface during the friction test, which can avoid the direct contact of the asperity. It is speculated that specific molecular orientations of these chemical adsorption films may be formed during the tribo-test; this is conducive to the realization of an ultra-low friction coefficient. However, the effects of the tribochemically adsorbed films are still not very clear, which need to be studied in future research.

The abovementioned results demonstrate that the realization of ultralow friction using an EAP solution with $50 \mathrm{wt} \% \mathrm{BZA}$ concentration not only depends on the effect of hydrodynamic lubrication, but also relies on the tribo-chemically adsorbed films on the frictional surface.

\section{Conclusion}

In summary, the lubricating properties of EAP solutions with different BZA concentrations on steel surfaces were investigated. The results reveal that with an increase in the BZA concentration in the solution, the friction coefficient is reduced obviously, and the contact pressure decreases significantly. In particular, ultra-low friction $(\mu \approx 0.005-0.008)$ is achieved when the BZA concentration in the solution reaches $50 \mathrm{wt} \%$. The ultra-low friction could be achieved when the applied normal load was $2-3 \mathrm{~N}$ and the sliding velocity was in the range from 
502.4 to $565.2 \mathrm{~mm} \mathrm{~s}^{-1}$. Based on the XPS analysis of the rubbing surfaces and the IR analysis of the solution with $50 \%$ BZA concentration, a tribochemical reaction occurs between the BZA molecules and iron ions, and the adsorbed tribochemical layers are formed, which can avoid the frictional surface from direct contact. In addition, the ultra-low friction of the EAP solution with $50 \mathrm{wt} \%$ BZA concentration is in the regime of mixed lubrication. Combining the results of these analyses, it can be concluded that both the influence of the hydrodynamic effect and the existence of chemically absorbed films lead to the reduction of the friction coefficient.

\section{Conflicts of interest}

We declare that there is no commercial or associative interest that represents a conflict of interest in connection with the work submitted.

\section{Acknowledgements}

The work was financially supported by the National Natural Science Foundation of China $(51335005,51527901,51605351)$.

\section{References}

1 M. Hirano and K. Shinjo, Phys. Rev. B: Condens. Matter Mater. Phys., 1990, 41, 11837-11851.

2 K. Shinjo and M. Hirano, Surf. Sci., 1993, 283, 473-478.

3 M. S. Tomassone, J. B. Sokloff and A. Widom, Phys. Rev. Lett., 1997, 79, 4798-4801.

4 J. B. Luo, B. Shi, L. M. Qian, S. Z. Wen and Y. W. Sha, Tsinghua Sci. Technol., 1997, 11, 106.

5 J. B. Luo and J. J. Li, Lubr. Eng., 2010, 35, 1-10.

6 J. J. Li and J. B. Luo, Sci. China: Technol. Sci., 2013, 56, 28772887.

7 J. M. Martin, C. Donnet, T. Lemogne and T. Epicier, Phys. Rev. B: Condens. Matter Mater. Phys., 1993, 48, 10583-10586.

8 A. Erdemir, Surf. Coat. Technol., 2001, 146, 292-297.

9 J. C. Sanchez-Lopez, M. Belin, C. Donnet, C. Quiros and E. Elizalde, Surf. Coat. Technol., 2002, 160, 138-144.
10 M. Dienwiebel, G. S. Verhoeven and N. Pradeep, Phys. Rev. Lett., 2004, 92, 126101.

11 U. Raviv and J. Klein, Science, 2002, 297, 1540-1543.

12 U. Raviv, S. Giasson, N. Kampf, J. F. Gohy, R. Jerome and J. Klein, Nature, 2003, 425, 163-165.

13 M. Chen, K. Kato and K. Adachi, Wear, 2001, 250, 246-255.

14 F. Zhou, K. Adachi and K. Kato, Diamond Relat. Mater., 2005, 14, 1711-1720.

15 J. J. Li, C. H. Zhang and J. B. Luo, Langmuir, 2011, 27, 94139417.

16 C. Matta, L. Joly-Pottuz, M. I. D. Bouchet and J. M. Martin, Phys. Rev. B: Condens. Matter Mater. Phys., 2008, 78, 085436.

17 J. J. Li, C. H. Zhang, L. R. Ma, Y. H. Liu and J. B. Luo, Langmuir, 2013, 29, 271-275.

18 J. J. Li, C. H. Zhang and J. B. Luo, Langmuir, 2013, 29, 52395245.

19 S. Arad, L. Rapoport, A. Moshkovich, D. van Moppes, M. Karpasas, R. Golan and Y. Golan, Langmuir, 2006, 22, 7313-7317.

20 J. J. Li, Y. H. Liu, J. B. Luo, P. X. Liu and C. H. Zhang, Langmuir, 2012, 28, 7797-7802.

21 J. J. Li, C. H. Zhang, M. M. Deng and J. B. Luo, RSC Adv., 2015, 5, 30861-30868.

22 K. Li, T. Amann, M. List, M. Walter, M. Moseler, A. Kailer and J. Ruhe, Langmuir, 2015, 31, 11033-11039.

23 K. Li, T. Amann, M. Walter, M. Moseler, A. Kailer and J. Ruhe, Langmuir, 2013, 29, 5207-5213.

24 M. Walter, T. Amann, K. Li, A. Kailer, J. Ruhe and M. Moseler, J. Phys. Chem. A, 2013, 117, 3369-3376.

25 A. E. Martell and M. Calvin, Metal Chelate Chemistry, Science Press, Beijing, 1964.

26 R. G. Charles and S. Barnartt, J. Phys. Chem., 1958, 62, 315318.

27 J. Conradie and E. Erasmus, Polyhedron, 2016, 119, 142-150.

28 J. J. Li, C. H. Zhang, M. M. Deng and J. B. Luo, RSC Adv., 2015, 5, 63827-63833.

29 D. Dowson and G. R. Higginson, Elasto-Hydrodynamic Lubrication, Pergamon Press, Oxford, 1977. 